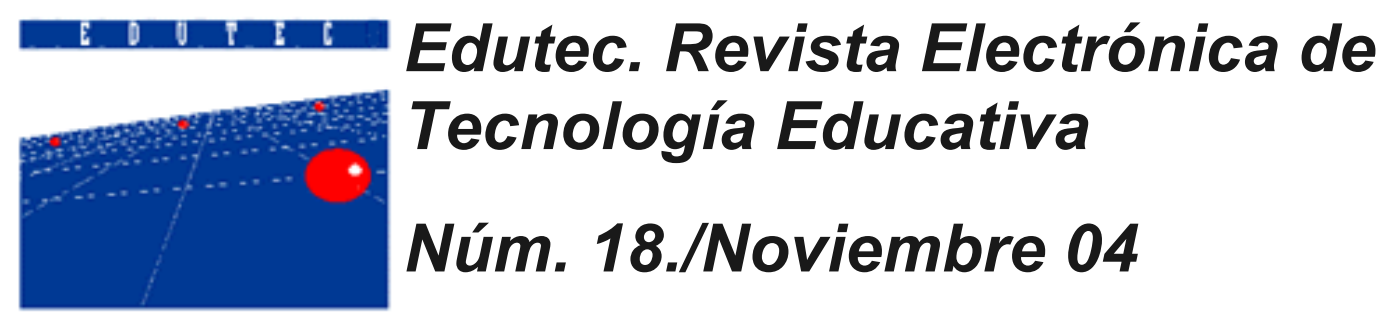

\title{
CAMBIOS ORGANIZATIVOS Y ADMINISTRATIVOS PARA INCORPORACIÓN DE LAS TICS A LA FORMACIÓN. MEDIDAS A ADOPTAR.
}

Julio Cabero Almenara

Universidad de Sevilla

cabero@us.es

http://tecnologiaedu.us.es

\section{1.- Algunas ideas previas.}

Frente a la idea tradicional que sugiere que para la incorporación de las TICs a los procesos de enseñanza-aprendizaje únicamente se deben adoptar medidas para su presencia y su utilización didáctica (metodologías, formas de diseño o formas de evaluación). La realidad es que los aspectos que podríamos considerar como organizativos y administrativos, son claves para su incorporación. Y son claves, independientemente de la tecnología a la que nos refiramos, a la tipología de enseñanza en la que se movilicen (formal, informal o no formal), o del nivel educativo en el que se inserten.

Dobrov (1979) en un trabajo clásico, hablaba que además de considerar el "hardware" y "software" como elementos constitutivos de los medios, deberíamos tener en cuenta uno nuevo: el "orgware"; o componente estructural de un sistema tecnológico, que tiene la misión de asegurar el funcionamiento de los anteriores, y garantizar la interacción con otros elementos y con otros sistemas de naturaleza diferente. Para este autor, todo sistema tecnológico requiere una forma específica de organización estructural, de manera que sin ella el diseño y el componente tecnológico, pueden resultar o inútil o perjudicial.

Este autor llega a definirlo como: "... el conjunto de medidas socioeconómicas, de organización y de gestión que están destinados a asegurar la identificación y la utilización eficaz de una técnica y de conocimientos científicos-técnicos dados, así como la capacidad potencial del sistema tecnológico, para adaptarse, desarrollarse y autoperfeccionarse." (Dobrov, 1979, 632).

En función de la importancia concedida a este nuevo componente, Dobrov divide la historia de la tecnología educativa en pasada, presente y futura. Las cuales las representa gráficamente en la figura $\mathrm{n}^{\circ} 1$, donde claramente podemos observar la importancia progresiva que ha ido adquiriendo este nuevo elemento. 

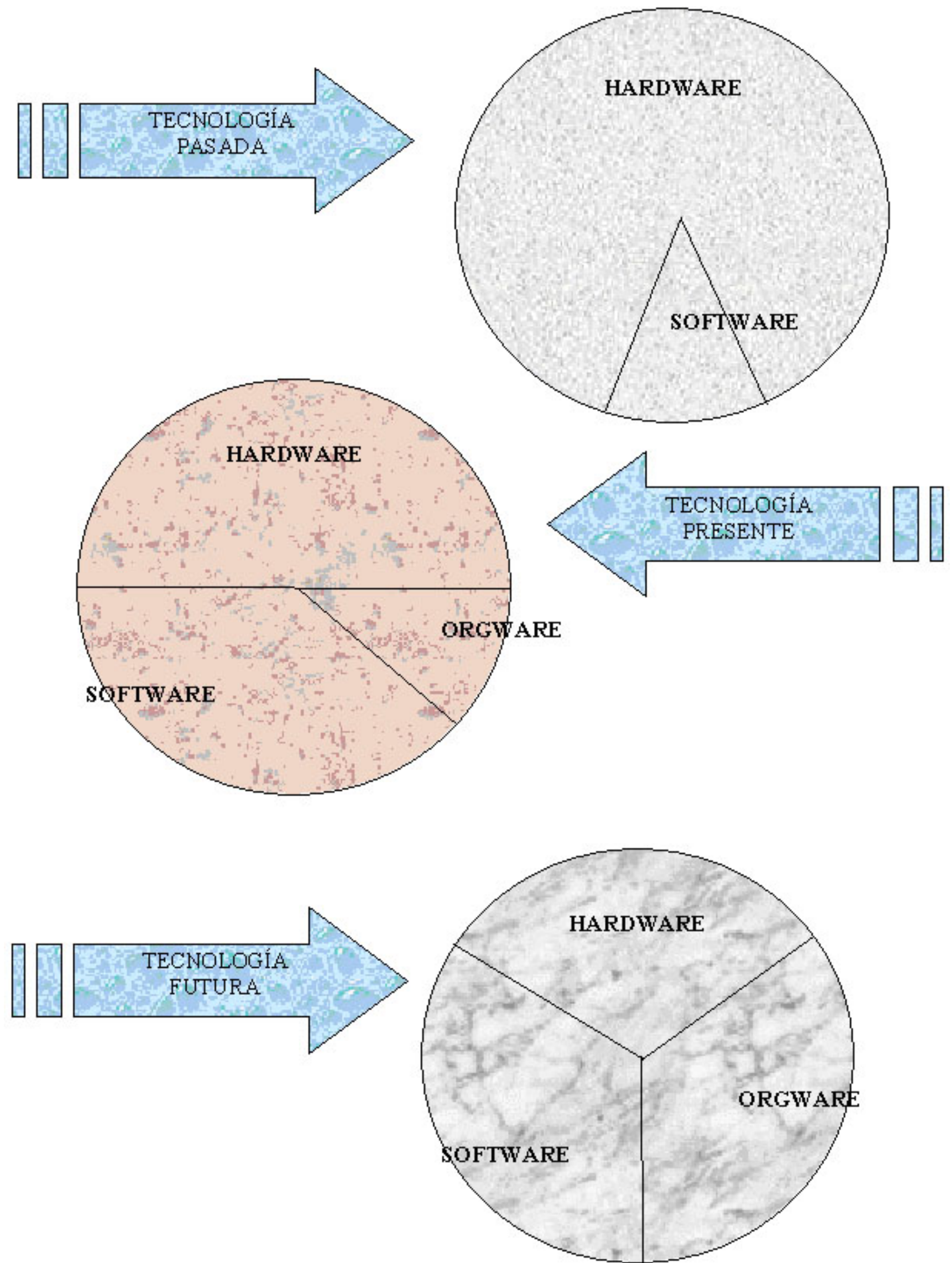

Fig. $n^{\circ}$ 1. Diferenciación histórica de la tecnología educativa según Dobrov $(1979,635)$.

Como señalan Blázquez y Martínez (1995, 447): “La organización de los recursos tecnológicos en los centros posee... mayor importancia de lo que pudiera parecer. Muchas veces se frustra su utilización, su inserción y explotación en la intervención curricular por no contar con esta importante condición". Por otra parte, no debemos olvidarnos que las tecnologías, sobre todo las que han sido consideradas como nuevas, transforman los modos, las formas, los espacios, los tiempos y las modalidades de interacción de los que participan en la acción educativa, y por ello requieren respuestas organizativas completamente diferentes a las que demandaban tecnologías pasadas para incorporase a situaciones donde existían una coincidencia espacio-temporal entre el 
profesor y el estudiante, y además este último por lo general era contemplado como un receptor pasivo de información, o mejor dicho un depositario de la misma.

La significación de esta dimensión organizativa es más trascendente de lo que a priori puede pensarse; así, por ejemplo en diferentes investigaciones que hemos realizado (Cabero, 1998 y 2001), los motivos que aluden los profesores para no utilizarlos, los podríamos encuadrar dentro de ella: inexistencia de un responsable de medios, falta de horarios flexibles de acceso, o no separación de medios disponibles para ser utilizados por el profesorado y por los estudiantes.

Por seguir insistiendo, en una investigación (Cabero, 1998) donde analizamos la utilización que los profesores andaluces realizaban de los medios audiovisuales, informáticos y de las nuevas tecnologías de la información, los motivos fundamentales que aludían para no incorporarlos a su práctica educativa eran:

1.- Falta de instalaciones adecuadas para su observación y audición (12.70\%).

2.- Falta de tiempo/amplitud de la programación educativa (9.44\%).

3.- Son difíciles de transportar al aula (9.31\%).

4.- Falta de presupuesto en el centro para adquirir material de paso $(8.60 \%)$.

5.- Excesivo número de estudiantes (6.50\%).

6.- No existe material de paso para la asignatura que imparto $(6.50 \%)$.

En el caso de los medios informáticos y las nuevas tecnologías las valoraciones que alcanzaron las puntuaciones más altas fueron las siguientes:

1.- Falta de formación para su utilización. (11.88\%).

2.- Falta de experiencia (11.05\%).

3.- Excesivo número de estudiantes $(8.81 \%)$.

4.- No conozco su funcionamiento técnico (8.345).

5.- Falta de instalaciones adecuadas para su observación y audición (7.46\%).

Datos muy similares obtuvimos también en otra investigación, pero esta vez centrada en el nivel universitario y realizada en diferentes Universidades españolas; allí nos encontramos que los motivos que los profesores apuntaban para su utilización eran como los siguientes: el 10,9\% $(f=370)$ la "falta de instalaciones adecuadas para su observación y audición", el 8,4\% ( $f=284)$ al excesivo número de estudiantes, y el $7.7 \%(\mathfrak{f}=260)$ la "falta de tiempo/amplitud de la programación educativa" (Cabero, 2002).

Creo que los datos apuntados, indican con toda claridad la importancia de contemplar las variables organizativas como elemento significativo para la incorporación de las TICs a la formación y a la investigación; sin olvidarnos, por otra parte, que esta se convertirá en factor determinante de calidad de la interacción que se produzca en el sistema.

Por otra parte también tenemos que percibir que las TICs provocan cambios en las propias organizaciones educativas, así por ejemplo, provocan un aumento de las interrelaciones entre los diferentes miembros de la comunidad, ofreciéndonos la oportunidad de una comunicación más fluida entre sus diferentes miembros. Ahora bien, ello por si mismo no es suficiente, como señala Kagel $(2003,279)$ : "Es necesario pensar el cómo se las implementa y qué idea subyace en esa implementación."

Pero antes de de realizar algunos comentarios respecto a su organización, quiero dejar claro desde el principio, que no voy a descubrir la piedra filosofal, ya que no existe una única forma de organizar y administrar los medios en las instituciones educativas, pues ello dependerá de una serie de variables, que irán desde el modelo organizativo que tenga el centro, la cultura escolar en la que se desenvuelva, el nivel educativo al cual nos estemos refiriendo, o la diversidad de tecnologías que puedan ponerse en funcionamiento.

En este aspecto de los modelos de centros, ya comentamos en otros trabajos (Duarte y Cabero, 1993; Cabero, 1996), que en función del tipo de centro educativo: tradicional o versátil, los medios se incorporarían de una forma específica. Así, si los modelos educativos de centros tradicionales, vienen configurados por características como: ser centros cerrados en sí mismo, dirección 
unipersonal, currículo uniforme, metodología indiferenciada, disciplina formal, evaluación discontinua, agrupamiento rígido de los alumnos, profesor autosuficiente, uniformidad del espacio, escasez de recursos, y uniformidad de horarios; y los versátiles, por ser centros abiertos al entorno, tener una dirección participativa, existencia de un currículo diferenciado, metodología individualizada, disciplina centrada en las exigencias de la actividad y de la relación social, evaluación continua, agrupamiento flexible de los alumnos, enseñanza en equipo, diversidad de espacio, abundancia de recursos para el aprendizaje, y horario flexible. En uno y otro, el comportamiento de los medios será diferente, como representamos en la figura $n^{\circ} 2$, y necesitará por tanto de respuestas organizativas distintas.

\section{MODELOS DE \\ ORGANIZACIÓN DE CENTROS}
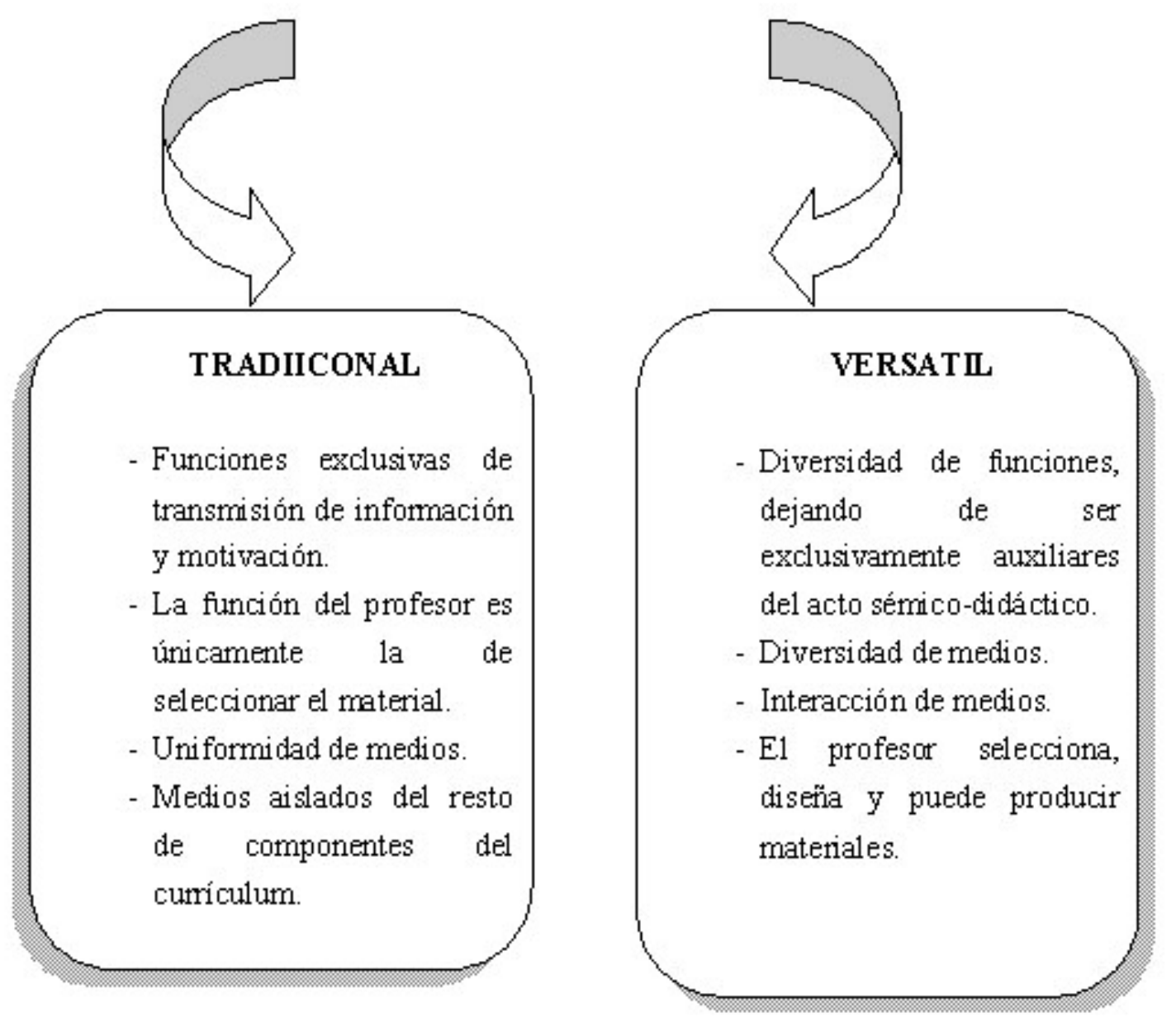

Fig. $\mathrm{n}^{\circ}$ 2. Modelos de organización de medios y utilización y funciones a desempeñar en la enseñanza. (Cabero, 1996, 408).

Teniendo en cuenta lo expuesto, en nuestra intervención nos centraremos en una perspectiva general, que deberá de ser adaptada en función del nivel educativo, la tipología de centro, la cultura imperante en los mismos, o que estemos hablando de una modalidad presencial de enseñanza, de aprendizaje a distancia en soportes virtuales o analógicos, o que nos estemos refiriendo a una situación combinada de presencialidad y virtualidad apoyada en las redes, en eso que se está comenzando a denominar como "aprendizaje mezclado".

Cuatro son los aspectos básicos que voy a tratar en mí intervención: qué aspectos facilitan la incorporación de las TICs, de qué formas podemos organizar los medios en los centros, cuál puede ser la funcionalidad de los centros de recursos; para finalizar ofreciendo algunas reflexiones sobre las posibilidades que las TICs pueden tener para la gestión y administración de las instituciones educativas. 


\section{2.- Aspectos que facilitarán su incorporación a la práctica educativa.}

Los aspectos que facilitarán su incorporación son diversos, y a grandes rasgos, y sin querer acotar el tema, podemos decir que son los siguientes:

1. Presencia física de las tecnologías.

2. Existencia de centros dinamizadores.

3. Creación de una cultura de utilización de las TICs.

4. Superar las incertidumbres que todo cambio provoca/Liderazgo.

5. Diversidad funcional.

6. Comunidades de profesores.

7. Alfabetización digital - Formación del profesorado y personal de administración y servicios.

\section{1.- Presencia física de las tecnologías.}

Lógicamente uno de los primeros aspectos a contemplar, es que las tecnologías se encuentren presente en las instituciones educativas, y debemos reconocer que aunque en uno más que otros, en todos los países, en todos los niveles educativos, y por todos los gobiernos, se han realizados esfuerzos en esta dirección, aunque algunas veces estos pudieran ser insuficientes.

Ahora bien, respecto a esta presencia tenemos que realizar una serie de matizaciones. La primera, es que la tecnología debe estar cercana y ser de fácil acceso para el profesorado y el alumnado, lo que quiero venir a decir con ello es que no es suficiente con crear aulas de informática, sino de cambiar el concepto de "aula de informática" a la "informática al aula", o de diferenciar entre "acceder a la red" y "formar parte de la red"; de forma que la tecnología se encuentre a disposición del profesorado cuando desee incorporarla a la práctica de la enseñanza, y sea él exclusivamente apoyándose en criterios metododológicos el que decida, o no, su incorporación. Soy de los que piensan que hasta que una tecnología no adquiera la característica de invisible, no está perfectamente integrada en las acciones formativas de los profesores; me explico, cuando nosotros entramos en un aula no miramos si existe o no una pizarra, asumimos que existirá, independientemente del tipo que sea, es decir, es una tecnología que ya es común, ya es invisible, para nuestra práctica educativa. Esto que ha pasado con la pizarra, empieza a ocurrir también en algunos centros con otras tecnologías, como por ejemplo con los retroproyectores, o con los ordenadores y los videoproyectores, en lugares específicos como los congresos y los eventos.

En este sentido, las nuevas tecnologías que están llamando a las puertas de las instituciones formativas, fundamentalmente las redes inalámbricas y los "bluetooth", más la reducción de los costos que está teniendo progresivamente la tecnología, favorecerán su presencia en los centros. Por otra parte, creo que en un tiempo no muy lejano, los ordenadores portátiles se convertirán en instrumentos usuales en los centros.

De todas formas no debemos caer en el error de pensar que la incorporación de las TICs se reduce a la incorporación de Internet. De una serie de medios que le presentamos a los profesores: video, retroproyectores, proyectores de diapositiva, magnetófonos, equipos de música, ordenador, equipo de videoconferencia, lector de documentos, videoproyector y fotocopiadora; tres son los que encontramos en nuestro estudio (Cabero, 2002 y 2003) que eran los preferidos por los profesores: los ordenadores, los retroproyectores y las fotocopiadoras. Aunque puede ser cierto que por la temporalidad de nuestro estudio, la presencia de Internet estaba comenzando, la realidad es que los profesores por lo general suelen tener otras preferencias para sus prácticas docentes, y aunque esta tecnología se ha incorporado plenamente como herramienta de comunicación e información y para la investigación, no lo está haciendo de la misma forma en la docencia.

Desde mi punto de vista esta presencia no debe limitarse exclusivamente al hardware, sino también, y puede que en el futuro sea lo verdaderamente importante, al software que mantiene su funcionamiento. La historia de los medios audiovisuales ha demostrado con creces, como algunos medios concretos han quedado obsoletos con un mínimo uso, simplemente por la falta de recursos para su utilización.

Este uso del software no debe limitarse al denominado de propósito general, sino que debe 
alcanzar al específicamente didáctico y educativo. Debemos dejar suficientemente claro que la utilización real de las TICs, se consigue cuando el profesor tiene a su disposición una diversidad amplia de objetos de aprendizaje para que seleccione el más adecuado al problema de comunicación con el que se enfrente; por ello puede ser de gran ayuda la potenciación de comunidades de profesores, para la producción y el intercambio de materiales. Comunidades que dada su importancia analizaré más específicamente después.

Esta presencia no debe limitarse a las instituciones educativas y laborales. Si de verdad queremos que no se produzca una brecha digital, con la marginación de aquellos que no tengan posibilidades de acceso a esas tecnologías en los espacios domésticos, se tienen que adoptar medidas claras para facilitar su presencia en los hogares mediante ayudas, subvenciones, o la disminución del costo de los equipos.

Como es conocido, no todos tenemos las mismas actitudes y habilidades hacia las tecnologías, existen personas que poseen lo que ciertos autores han denominado como "tecnofobia", de ahí que sea útil la creación de servicios de apoyo y resolución tecnológica de problemas a los profesores. Creo que dentro de las plantillas de personal de las instituciones educativas, se deben crear puestos de técnicos en audiovisuales, informática y telemática, que ayuden al profesorado a la resolución de los problemas tecnológicos que vayan surgiendo, desde la limpieza de los fastidiosos virus informáticos, hasta la configuración de los ordenadores adecuándolo a los nuevos programas informáticos, sin olvidarnos de los tediosos cambios de lámparas. Es decir, las instituciones educativas tendrán que actualizar los perfiles de sus plantillas técnicas y administrativas a las nuevas necesidades que vayan emanando de la evolución científica de la sociedad.

La experiencia realizada en la Universidad de Sevilla, con la creación de un servicio denominado SOS, ha tenido una consecuencia positiva para que los profesores que tenían respeto por la tecnología, se hayan acercado a ellas. En concreto este servicio ofrece ayudas al profesorado para la atención y resolución de consultas o peticiones relacionadas con los ordenadores (adquisición, instalación de equipos, e instalación de paquetes legalmente adquiridos), las incidencias producidas en el uso de ordenadores y redes (problemas de funcionamiento en general y los problemas con los programas, tanto de los paquetes como de las aplicaciones corporativas de gestión) y de redes de voz y datos (altas, traslados, de líneas o equipos (teléfonos móviles inclusive), averías y cambios de categoría).

Por último señalar que se va a producir una fuerte transformación de las tecnologías analógicas a las digitales, y a las digitales abarcando a los diferentes tipos de medios, desde los impresos a los audiovisuales, sin olvidarnos de los auditivos y telemáticos. Ello implicará una serie de transformaciones en lo referente a las posibilidades que lo digital tiene sobre lo analógico: interactividad, interconexión, influencia más en los procesos que en los productos,...

\section{2.- Existencia de centros dinamizadores.}

En cierta medida relacionado con lo anterior, nos encontramos con la creación de centros de recursos que ayuden a la penetración de las TICs en los contextos educativos. Centros que dada su importancia para la organización y administración de las TICs, nos detendremos posteriormente en analizarlo, por ello aquí diremos exclusivamente dos aspectos: uno, que deben cumplir diferentes funciones: instrumental, informativa, formación y asesoramiento del profesorado, selección y evaluación de medios, investigación,... (Cabero, 1996); y dos, que en su configuración deben estar formados por dos tipos de personal como mínimo: expertos en el manejo técnico de los medios y expertos en su diseño y utilización didáctica.

\section{3.- Creación de una cultura de utilización de las TIC - Diversidad funcional.}

Las posibilidades que las TICs pueden aportar a la formación no se agotan en su utilización como herramienta transmisora de información, sino que si de verdad queremos que se conviertan en elementos transformadores de la acción educativa, se debe potenciar la utilización de la información electrónica a todos los niveles, desde la comunicación entre las personas que trabajan en el centro educativo, a la gestión y administración del centro, pasando por las actividades relacionadas con la investigación, sin olvidarnos de su utilización en los procesos de enseñanza- 
aprendizaje.

Creo que una de las formas de potenciar la incorporación de las TICs, es que se perciba la diversidad de funciones que pueden realizarse a través de ellas: comunicación entre los profesores, realización de actas, secretaría virtual, solicitud de libros a las bibliotecas, revisión de las revistas, ofrecer la historia fotográfica de la institución educativa,.... La utilización de estas funciones, nos llevarán a ganar tiempo, ahorrar energía, alcanzar fiabilidad, y nos permitirá liberarnos de acciones tediosas y aburridas.

El simple hecho de que la comunicación entre la dirección y los profesores del centro sea fundamentalmente virtual, facilita un cambio de cultura y propicia que se vaya perdiendo el miedo a las tecnologías, y que se extienda su utilización a otros aspectos no meramente informativos y comunicativos, sino de administración, control y docencia. Al mismo tiempo su utilización tiene un valor añadido: utilizar las herramientas de comunicación de la sociedad del conocimiento.

En este sentido, el problema puede ser cuándo y cómo hacemos el cambio. Mi experiencia, es que debe de ser progresivo, para facilitar el cambio de la cultura impresa a la cultura mediática. Aunque con ello no queremos decir que sea demasiado lento, como para que los implicados no adopten medidas para aprender el manejo de las nuevas tecnologías y cambien conductas y aptitudes de otros momentos históricos.

Desde mi punto de vista facilita la creación de una cultura mediática el hecho de establecer medidas, que permitan que no sólo seamos receptores de información, sino también productoras de las mismas. Me explico, que no sólo podamos consultar el tablón de anuncio virtual del centro para informarnos del horario escolar o las nuevas normativas, sino también, que nosotros podamos informar de una serie de aspectos: congresos que organizamos, demandar materiales específicos para la docencia,...

\section{4.- Superar las incertidumbres que todo cambio provoca/Liderazgo.}

La experiencia ha demostrado que cada vez que se realiza un cambio en las instituciones educativas, éste provoca una incertidumbre que dificulta su utilización y adopción por las personas y por la cultura que la dirige. Y ello solamente puede superarse con la adopción de medidas claras para su incorporación, motivando a su utilización, y con capacidad de liderazgo. Como señala Bates $(2001,126)$ : "Los profesores sólo cambiarán si pueden ver claramente los beneficios del cambio y las desventajas de no cambiar. Cualquier estrategias para poner en práctica el uso de la tecnología para la enseñanza y el aprendizaje, debe tener en cuenta la cultura dominante de la Universidad, y sobre todo la de los miembros del claustro".

Algunos de las experiencias que hemos realizado en nuestra Universidad, nos han llevado a que se produzcan cambios en el profesorado, por el simple hecho de que algunos profesores han participado en ciertas experiencias en los departamentos y centros y los demás con el paso del tiempo no han querido quedarse relegados de lo que hacían sus compañeros con sus alumnos: ubicar los programas en la red, utilizar presentaciones colectivas informatizadas, o realizar tutorías virtuales.

Kagel $(2003,86-88)$ ha aportado recientemente una lista de algunas variables que pueden presentarse como dificultadoras de la incorporación de las tecnologías. Independientemente de sus aportaciones concretas, lo interesante es el comentario referido a que las dificultades no sólo se dan en una dirección, sino en varias: docentes, institución, directores, comunicación, desestructuración de los espacios, viabilidad y flexibilidad del proyecto, y padres. En concreto su aportación sería:

* Docentes (Conservadorismo, cambio de rol, miedo del docente a perder lo conseguido, en muchos casos los docentes son superados por los alumnos, y falta de comprensión por parte del docente del proyecto). 
* Institución (Defensa hacia lo nuevo, la cultura institucional pase en contra a los cambios, la necesidad de tener resultados inmediatos para "poder mostrar", y los valores del proyecto no eran congruentes con las personas involucradas de forma inmediata.

* Directores (Si el cambio proviene de la entidad propietaria y ésta lo impone, los directivos lo ven como una crítica a su gestión, y apoyo por los directivos pero sin compromiso.

* Comunicación (La poca comunicación del proyecto y la comunicación se daba por sectores y fraccionada.

* Destrucción de los espacios (Los espacios significan en las instituciones escolares, símbolos de poder de las áreas que lo sustentan. Por lo tanto la desestructuración de los mismos iba a poner a prueba los espacios de poder.

* Viabilidad y flexibilidad del proyecto (Las presiones de fecha límites poco reales generó estrés...

* Padres (La ansiedad de los padres que no veían resultados inmediatos y la ausencia de computación tradicional).

Señalar también que la experiencia demuestra que la capacidad de liderazgo institucional para utilizar las TICs, es un elemento significativo para potenciar su incorporación, y romper los miedos y recelos que los profesores suelen tener hacia las mismas. El simple hecho de potenciar la comunicación electrónica entre las autoridades académicas y el profesorado, facilita que este último adquiera el hábito de utilizar otras herramientas de comunicación diferente a la verbal e impresa. En el informe elaborado por la Comisión Especial de estudio para el Desarrollo de la Sociedad de la Información (MCT, 2003) donde se analiza la penetración de ésta en la sociedad española, se apuntan una serie de barreras que limitan la sociedad de la información, y entre ellas claramente se indica la influencia de la insuficiencia del liderazgo ejercido por los poderes públicos.

Por continuar en esta línea, determinadas experiencias que se están desarrollando en la Unión Europea para incorporar las TICs a los centros de formación pasan por capacitar, motivar y transformar, las percepciones de los directores de los centros tienen respecta a como elemento básico para la incorporación de las TICs: "Es esencial que los directores/as de centros comprendan los problemas que plantea la adopción de las TIC, porque es probable que su plena integración exija cambios en los horarios y la estructura de los centros, además de tener implicaciones en los recursos" (MECD, 2003, 159).

\section{5.- Comunidades de profesores.}

Para la utilización de las TICs puede ser de gran ayuda la creación y potenciación de las denominadas "comunidades de profesores"; es decir la conjunción de un grupo de profesores que compartan los mismos valores, similares concepciones de la enseñanza, y lleguen por tanto a intercambiar experiencias e información, y produzcan materiales educativos que puedan ser utilizados por el grupo. En este sentido es necesario pasar de una cultura de trabajo individual, a una cultura del trabajo colaborativo y cooperativo. $Y$ ello resulta algunas veces muy complejo en nuestras instituciones educativas, sobre todo en los de niveles universitarios, donde los profesores suelen tener algunos problemas para trabajar en equipo, y se comportan de forma aislada.

La creación de estas comunidades de aprendizaje pueden ser más sugerentes, si tenemos en cuenta que uno de los mayores inconvenientes que suelen indicar los profesores que se encuentran a la hora de incorporar las TICs a la práctica educativa, es la falta de materiales educativos. En este sentido podría ser útil trabajar con el concepto de "objetos de aprendizaje", que son: "cualquier recurso digital que puede ser usado como soporte para el aprendizaje" (Chan (2002, 112). Objetos que deben poseer una serie de características: ser reutilisable, interoperable, fácil de manejar en diferentes niveles de complejidad en ambientes instruccionales y con posibilidad de ensamblarse. 
Los objetos no sólo tienen que limitarse a materiales mediados, sino que también, pueden incluir diferentes recursos: ambientes problemáticos, estudios de casos, "cazas de tesoro", "webquest", modelos interactivos, problemas instruccionales, conjuntos de problemas, módulos con función instruccional, módulos con rutinas para la instrucción: asesoría, retroalimentación, mensajes instruccionales, rutinas modulares para la representación de información, simulaciones, y módulos lógicos con propósitos instruccionales.

\section{6.- Alfabetización digital - Formación del profesorado y personal de administración y servicios.}

Lo comentado hasta el momento no es posible de desarrollar si las personas que trabajan en las instituciones educativas, no presentan unas actitudes y aptitudes favorables para la utilización de las TICs; es decir, sino presentan un alto dominio en eso que se ha venido a denominar como alfabetización digital o mediática que "se refiere a un sofisticado repertorio de competencias que impregnan el lugar de trabajo, la comunidad y la vida social, entre las que se incluyen las habilidades necesarias para manejar la información y la capacidad de evaluar la relevancia y la fiabilidad de lo que busca en Internet" (MECD y la OCDE, 2003, 80).

Como estamos viendo el concepto de alfabetización mediática, es más amplio que el simple hecho de saber manejar un ordenador, como tradicionalmente se ha entendido y se sigue entendiendo por ciertos sectores. En cierta medida es la separación entre el concepto de saber la mecánica de un coche y saber conducirlo.

Desde nuestro punto de vista, esta alfabetización, debe facilitar la creación de personas competentes al menos en tres aspectos básicos: manejar instrumentalmente las tecnologías, tener actitudes positivas y realistas para su utilización, y saber evaluar sus mensajes y sus necesidades de utilización. Al mismo tiempo no debemos olvidarnos la sugerencia que realiza Martínez (2002, 54) al llamarnos la atención respecto a que deberemos adquirir una actitud y aptitud intercultural: "Actitud para aceptar otros puntos de vistas y otros sistemas de organización social y, con ellas, de representación, así como otras significaciones de los signos y las conductas que podríamos caer en la tentación de considerar como propias. Pero para trabajar dentro de entornos interculturales no basta con querer hacerlo, también es necesario disponer de las aptitudes que haga posible ese deseo y ello tiene que ver con los conocimientos necesarios para poder reconocer, valorar e interpretar sistemas diferentes de organización social, y con ellos, de comunicación. En definitiva, tener la formación necesaria para conocer y reconocer culturas diferentes con las que pretendemos interactuar en nuestro proceso de aproximación al conocimiento."

Su extensión no debe centrarse exclusivamente en los profesores, sino que debe alcanzar a todo el personal implicado en el sistema educativo, desde los alumnos, hasta el personal de administración y servicios, sin olvidarnos de los cargos de gestión, sobre los que fundamentalmente se deberá hacer una transformación en los cambios de mentalidad si de verdad queremos que cumplan la función de líderes a la que anteriormente hacíamos referencias.

La formación del profesorado, es una de las cuestiones básicas para la incorporación de las TICs. En el trabajo de investigación que realizamos sobre la utilización de las TICs en la Universidad (Cabero, 2002 y 2003), los profesores reconocían mayoritariamente $(68,3 \%)$ que no se encontraban formados técnicamente para su utilización; el porcentaje se incrementaba cuando la pregunta se refería a su formación para la utilización didáctica, en este caso las respuestas negativas alcanzaban el $74,2 \%$. Estos resultados pueden extenderse a diferentes contextos y situaciones, pues no conozco ningún trabajo de investigación realizado, tanto sobre contextos universitarios como no universitarios, que hayan dado resultados positivos en cuanto a la formación que el profesorado afirma tener para la utilización de las TICs.

Ya he realizado diferentes trabajos sobre la formación del profesorado y las TICs (Cabero, 1989 y Cabero y otros, 1999), y a ellos voy a remitir al lector interesado, diré aquí solamente que para mí esta formación debe superar la visión instrumental que muchas veces tenemos de la misma, y tiene que adquirir otras dimensiones: instrumental, semiológica/estética, curricular, pragmática, 
psicológica, productora/diseñadora, seleccionadora/evaluadora, crítica, organizativa, actitudinal e investigadora. Así como también debe realizarse siguiendo una serie de principios: el valor de la práctica y la reflexión sobre la misma, la participación del profesorado en su construcción y determinación, su diseño como producto no acabado, centrarse en medios disponibles para el profesorado, situarse dentro de estrategias de formación más amplias que el mero audiovisualismo y alcanzar dimensiones más amplias como la planificación, diseño y evaluación, y fomentar la coproducción de materiales entre profesores y estudiantes. Respecto al componente práctico, debe procurarse poner en ejercitación en contextos naturales, y que puede alcanzar diferentes perspectivas que van desde la autoexpresión, como método de aprendizaje y como deconstrucción de medios ya elaborados en otro momento por otros autores.

Esta formación será más necesaria si tenemos en cuenta que a diferencia de las tecnologías tradicionales, el comportamiento que tienen las denominadas como nuevas, dependerá bastante de la formación que tenga la persona para interaccionar con ellas. Valga como ejemplo de lo que queremos decir, que personas con bajos niveles de capacitación, únicamente utilizarán la red como elemento de búsqueda de información, mientras que otras con formación más elevadas, llegan a producir objetos de aprendizaje, formaran parte de comunidades virtuales y llegaran a utilizarla como instrumentos para el trabajo colaborativo.

Esta formación, que se hace más necesaria cada día y debe superar el centrarse exclusivamente en los medios, ya que como señalamos en otro trabajo (Cabero, 2001), los nuevos entornos potenciados por la incorporación de las TICs, tendrá una serie de repercusiones en el profesorado, modificando y ampliando algunos de los roles que tradicionalmente había desempeñado: consultor de información, facilitadotes de información, diseñadores de medios, moderadores y tutores virtuales, evaluadores continuos y asesores y orientadores; y puede que no todos estén preparados para asumirlos, tanto desde un punto de vista práctico como técnico, y conceptual y actitudinal. Por otra parte en entornos de teleformación el profesor se encontrará con tres grandes roles: proveedores de contenidos, tutores, y el de administrador o pertenencia al nivel organizativo de la actividad. Como ha sinterizado Barberá y otros $(2001,59)$ con estas nuevas tecnologías el docente "... se convierte en un animador de la inteligencia colectiva de los grupos de que se responsabiliza. Desde este punto de vista, su actuación se dirige al acompañamiento y gestión del aprendizaje: incitación al intercambio de conocimientos, mediación relacional y simbólica o al pilotaje personalizado de los recorridos de aprendizaje."

Respecto a los alumnos también es necesario que tengan un mínimo de competencias, en este caso Salinas $(2003,9)$, nos indica cuatro grandes tipos de destrezas:

a) Destrezas y conocimientos específicos destinados a las TIC: gestionar la información; comunicar; utilizar los interfaces hombre-máquina efectivamente; comprender como se trabaja autónomamente; saber cómo utilizar aplicaciones de software profesional, ...

b) Destrezas y conocimientos relacionados con las TIC como medios de información: ser capaz de leer, producir y procesar documentos, multimedias incluidos; procedimientos de comunicación (aprender cómo seleccionar o transmitir información); buscar, organizar y criticar la información; estructurar realidad concreta vs. realidad virtual, etc.

c) Destrezas y conocimientos relacionados con las TIC como temas de estudio en la escuela; usa nuevas representaciones del conocimiento en un tema dado; usar simulaciones y modalizaciones; procesar información emanada de varias fuentes y orígenes; desarrollar procedimientos operativos relacionados con dominios específicos del conocimiento; construir destrezas y conocimiento básico existente; reforzar las destrezas de comunicación; fomentar creatividad; etc.

d) Destrezas y conocimientos relacionados con las TIC como el status del conocimiento: anticipar cambios en el status de conocimiento; reforzar el potencial de transdiciplinariedad de las TIC; ayudar a la creación y a montar proyectos pedagógicos para todos los niveles educativos estudiantes, profesores, ...; apoyar el trabajo colaborativo/cooperativo,...

También nos gustaría llamar la atención respecto a un aspecto que se está dando con las nuevas tecnologías, y que puede tener repercusiones negativas para su incorporación educativa, y es que el profesor debe aprender a saber gestionar el tiempo, y diferenciar entre tiempo profesional-laboral y tiempo personal-familiar. Por decirlo en términos muy claros, tan malo puede ser aquel profesor que nunca contesta ningún correo electrónico, como el que siempre está contestándolos. Los alumnos deben aprender que el profesor no siempre debe estar siempre conectado ni disponible en la red. 
mínimas competencias para poder garantizar, por una parte que las tecnologías se utilizan para una diversidad de funciones, y por otra, para crear verdaderos centros tecnológicos. Desde una perspectiva sistémica, el sistema no funciona si algunos sectores no se encuentran implicados y capacitados para interaccionar en el mismo.

\section{3.- La organización de los medios en los centros.}

Digamos desde el principio que la organización de los medios en los centros podemos abordarla desde diferentes perspectivas:

1.- Cada profesor guarda el material didáctico en su aula.

2.- El material de uso común se centraliza en un depósito o almacén.

3.- El material se centraliza en un depósito o almacén por ciclos o por seminarios.

4.- El material se centraliza y se utiliza en espacios acondicionados a nivel central.

5.- El material se centraliza y se utiliza en espacios de aprendizaje por ciclos y áreas-materias. (Vidorreta e Igualada, 1986, 14-17).

Cada una de ellas, posee sus ventajas (facilidad, inmediatez de uso, amortización por utilización de los equipos adquiridos, evitar duplicaciones...) e inconvenientes (nadie se responsabiliza directamente del mantenimiento de los equipos, necesidad de catalogación-difusión del material existente...). Y deben por tanto asumirse con precaución.

De cara a su organización debemos diferenciar entre material de equipo y de paso, y dentro del primero establecer distintos niveles de dificultad y frecuencia de uso. Respecto al material de equipo, la primera cuestión a abordar a la hora de su organización es determinar aquellos más utilizado por los profesores del centro (retroproyector, proyector de diapositivas, equipos de vídeo...); éstos deberán estar lo más próximos posibles al aula, y si la situación económica lo permite dentro de las mismas; como ya comentamos anteriormente con el concepto de la "informática al aula". Si esto no fuese posible, mediante dispositivos móviles, se deben poner a disposición con facilidad para los profesores, sin la necesidad de desplazamientos complejos y dificultosos.

Aunque no existen, o por lo menos nosotros lo desconocemos, investigaciones que analicen la significación en el rendimiento, interacción didáctica, motivación, atención del alumno..., del desplazamiento de los alumnos del aula a salas específicas de audiovisuales, creemos que en la medida de lo posible, el audiovisual y la informática debe estar integrado en la propia aula y práctica cotidiana del docente y discente. Las otras estrategias, nos tememos que plantean problemas de disciplina y de utilización racional-didáctica de los medios por parte del profesor, más preocupado por el cuándo volverá a poder utilizar el aula, que por la actividad curricular que está llevando a cabo.

Esto no significa que no deban existir zonas específicas para los audiovisuales y nuevas tecnologías de la información y comunicación en los centros; deben existir, pero no fundamentalmente para realizar actividades directamente implicadas en las funciones de transmisión de información, motivación, ilustración, evaluación... del acto didáctico. Estas zonas, o salas de audiovisuales, deben a nuestro parecer, reservarse para ubicar y utilizar el material de frecuencia no muy usual: equipos de montaje en vídeo, equipos de locución, equipos de producción multimedia,... Materiales de uso discontinuo en los centros deben disponerse en centros de recursos locales o comarcales, ubicar en los centros equipos de visionado en formatos semi y profesionales, o equipos de sincronización de proyectores de diapositivas, para ser utilizado una o dos veces en el curso académico, es un claro error económico. Sin olvidar que el avance tecnológico hace que dichos equipos, a medio o corto plazo puedan quedar obsoletos, sin haberle sacado la máxima rentabilidad.

Puede ser importante, crear una cultura en el centro para progresivamente ir digitalizando los materiales y ubicarlos en la red, de formas que presentaciones colectivas informatizadas, clip de vídeos, documentos en pdf, etc.; puedan ser utilizado por todos los profesores con facilidad. Ello nos llevaría a la creación de un depositario de objetos de aprendizaje, donde, por una parte, los profesores y alumnos seleccionaran los que en el momento concreto de la actividad educativa 
vayan a necesitar, y por otra parte, utilizando las comunidades de profesores a la que anteriormente hicimos referencia, los profesores construyan y aporten entre todos, diferentes tipos de materiales de enseñanza, que puedan ser utilizados por todos.

Diversas propuestas de dotaciones han sido realizadas en diferentes congresos, jornadas y encuentros, nosotros aquí no vamos a realizar ninguna, porque creemos que ello dependerá, por una parte del centro concreto, y de su situación económica. Sin embargo sí nos gustaría citar algunas características que deben tener los medios que se ubiquen en los centros, pero siempre partiendo de una premisa concreta: medios más sofisticados no suponen más eficacia en el aprendizaje. Como características generales podemos citar:

- No solo deben servir a los profesores, sino también facilitar su utilización por los alumnos. Ya hemos señalado anteriormente que los alumnos no sólo deben ser consumidores de mensajes mediados, sino también productores de los mismos, y que la manera más eficaz de desmitificar lo medios es utilizándolos. Muchas veces el problema de la educación no radica en lo que se comunica, sino en lo que deja de comunicarse, impidiendo con ello el desarrollo futuro de capacidades o la utilización de habilidades o instrumentos presentes en la sociedad.

- Fácil manejo.

- Favorecer los enfoques multimedia.

- Características técnicas adecuadas: luminosidad, volumen, calidad de imagen, tamaño, consistencia.

- Flexibilidad, para poder ser usados en diferentes condiciones.

- Facilidad de localización de material para las reparaciones y el mantenimiento.

- Cubrir no sólo los aspectos de "hardware" del medio, sino también el "software".

- Utilizar al máximo los materiales digitalizados o digitalizables.

- Y análisis de costo de mantenimiento.

Las estrategias que se han sugerido para la organización de los medios en el sistema educativo son diversas. Lorenzo (1996) por su parte, habla de tres modalidades básicas: los talleres y rincones, los departamentos de actividades complementarias y extraescolares, y los denominados centros de recursos; que se sitúan a niveles diferentes de complejidad y que poseen criterios específicos para su puesta en funcionamiento. En el cuadro $n^{\circ} 1$, se sintetizan sus características básicas. 


\begin{tabular}{|c|c|c|c|}
\hline CRITERIOS & TALLERES/ZONAS & DEPARTAMENTO & $\begin{array}{l}\text { CENTROS DE } \\
\text { RECURSOS }\end{array}$ \\
\hline Incidencia & Aulas & Centro & Comarca-Intercentro \\
\hline Complejidad & Mínima & $\begin{array}{lll}\text { Similar a otras } \\
\text { unidades }\end{array}$ & Máxima \\
\hline Participación & $\begin{array}{l}\text { Profesor } \\
\text { Alumnos }\end{array}$ & $\begin{array}{l}\text { Profesores } \\
\text { Padres } \\
\text { Alumnos }\end{array}$ & $\begin{array}{l}\text { Profesores de varios } \\
\text { centros - Padres- } \\
\text { alumnos y otros. }\end{array}$ \\
\hline Apoyo/asesoramiento & Interno & Interno & Externo \\
\hline $\begin{array}{l}\text { Representación del } \\
\text { profesorado }\end{array}$ & Total & Cuasi total & Parcial \\
\hline Usuarios & Alumnos & Alumnos-Profesor & $\begin{array}{l}\text { Alumno-Profesor- } \\
\text { Comunidad. }\end{array}$ \\
\hline $\begin{array}{l}\text { Dependencia } \\
\text { institucional }\end{array}$ & Equipo docente & $\begin{array}{l}\text { Jefe de estudio- } \\
\text { Director }\end{array}$ & $\begin{array}{lr}\text { Director } & \text { Territorial- } \\
\text { Delegado } & \text { de } \\
\text { Educación. } & \end{array}$ \\
\hline
\end{tabular}

Cuadro $n^{0} 1$. Características de los modelos básicos de organización de los recursos didácticos (Lorenzo, 1996, 15-16).

En cuanto a los talleres o rincones, Lorenzo $(1996,21)$ llama la atención, respecto que además de ser una técnica didáctica suponen un procedimiento de selección, organización y distribución de materiales y recursos que tienen la ventaja de ser sencillo, fácilmente disponible para los alumnos, orientados hacia actividades concretas, y distribuidos en espacios cercanos por temas o áreas de conocimiento.

Esta distribución del aula por rincones, tiene sus predecesores en autores que provienen del movimiento de la "Escuela Nueva" con Dewey, Freinet, o Pestalozzi. No debemos de olvidar que la organización del aula por rincones, supera con creces la perspectiva de organización de los medios, y supone una organización psicológica y educativa del acto docente que para Laguía y Vidal (1987) se apoya en tres ideas básicas:

a) La educación de la autonomía (el alumno es responsable y desarrolla una actividad física y cognitiva de forma autónoma).

b) La individualización (permite un seguimiento individualizado o en pequeños grupos por parte del profesor).

c) La ruptura del trabajo intelectual y manual (se valora de idénticamente la actividad mental como la física).

Mientras que respecto a los departamentos de actividades complementarias y extraescolares, Lorenzo $(1996,25)$ indica que: están ubicados los recursos del centros con vistas a su mayor racionalización y aprovechamiento, dada sus características de visibilidad y sonoridad posibilitan un uso adecuado de los mismos, permiten el trabajo del alumno en situaciones flexibles de agrupamiento, los profesores tienden a enseñar activamente en los mismos, y se diseñan y producen materiales adecuados a las características y necesidades de los alumnos.

Para nosotros estas modalidades requieren la existencia de responsables de tecnologías en los centros, que pueden ser desde profesionales del terreno de los medios audiovisuales, informáticos o de Ciencias de la Información, hasta licenciados en Ciencias de la Educación que hayan cursado 
disciplinas relacionadas con la Tecnología Educativa. Entre las funciones que podrían desempeñar estarían las siguientes: conservación y mantenimiento físicas de los equipos, coordinación de su utilización, dinamizador para su uso, formación y reciclaje de los profesores de la zona, colaboración con el profesorado para la producción de materiales y objetos de aprendizaje específicos, favorecer la creación de comunidades de profesores, información de nuevas adquisiciones, grabación de programas educativos emitidos por tv, y organización de los fondos audiovisuales e informáticos del centro.

Las nuevas situaciones que se generan con las nuevas tecnologías, van a exigir el tener cada vez más especialistas técnicos en los centros para ayudar al profesorado y facilitar al mismo tiempo el mantenimiento del sistema. Ya que posiblemente la calidad y fiabilidad del sistema no se pueda mantener exclusivamente con el trabajo de los docentes, puesto que el nuevo entramado educativo será muy tecnificado, e interactivo entre hombres y máquinas (fig. $n^{\circ} 3$ ).

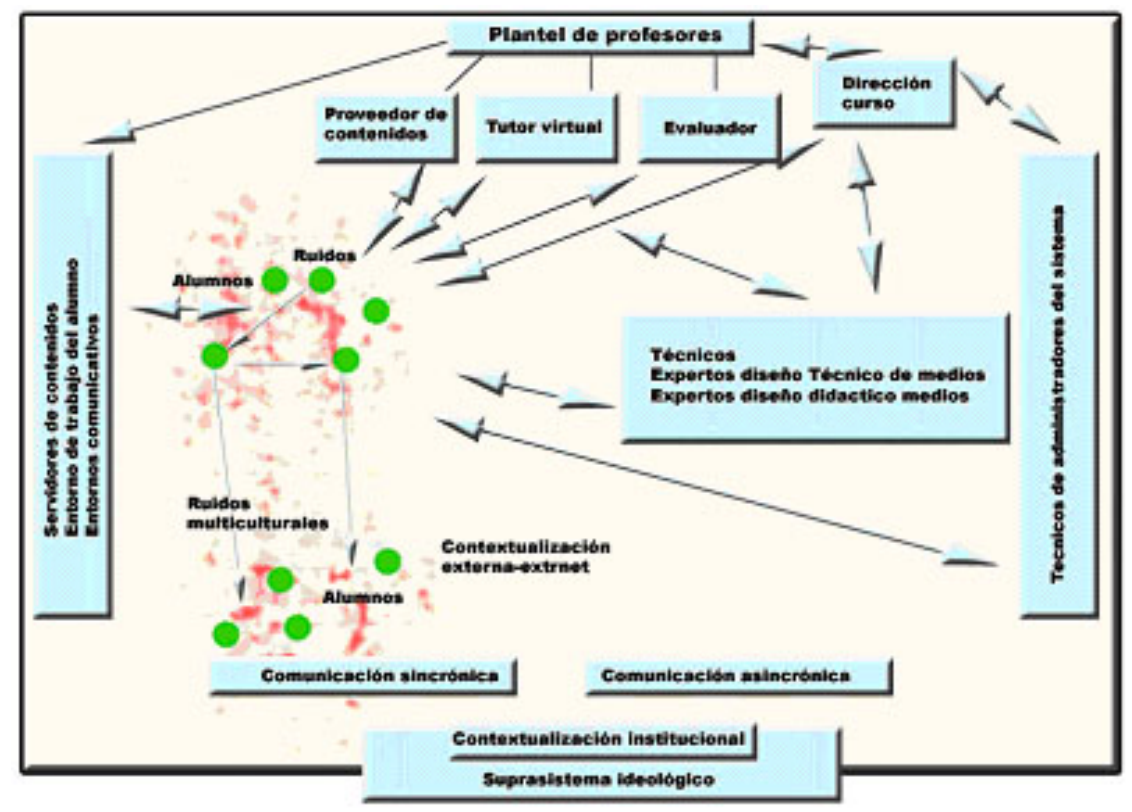

Fig. $n^{\circ}$ 3. Nuevo entramado tecnólogico-humano como consecuencia de la implantación de las nuevas tecnologías en los centros educativos.

Algunos de los comentarios realizados hasta el momento nos llevan a proponer la necesidad de contar en los centros con coordinadores de TICs, que faciliten su incorporación, control y utilización. Y al respecto cabe hacernos dos preguntas: ¿Qué características deben poseer? y ¿Qué funciones deben desempeñar?.

Respecto a la primera, creo que no importante es no hablar de titulaciones sino más bien, que posea dos características básicas:

- Dominio de tecnologías desde un punto de vista instrumental, de diseño/producción y de utilización didáctica de las TICs.

- Dinamizador - facilitador para la incorporación de las TICs en la enseñanza.

Y en la segunda, asumir las siguientes funciones:

- Coordinación, gestión mantenimiento básicos de los equipos.

- Asesoramiento y capacitación didáctica de los profesores del centro.

- Producción y elaboración de ciertos medios, sólo o en coordinación con otros responsables.

- Apoyar al profesorado para la integración de las TICs en la enseñanza.

- Dinamizador para la incorporación - integración de las TICs.

- Dinamizador/creador de comunidades entre profesorado de los centros.

- Análisis de las necesidades formativas de los profesores en las TICs.

- Análisis de las necesidades en materia de las TIC para el centro.

- Puente entre el centro y la Administración educativa en materia de TICs. 


\section{4.- Los centros de recursos.}

La expresión "centro de recursos" ha estado y está en cierta medida de moda, ahora bien ¿qué es realmente un centro de recurso? Las denominaciones que han sido utilizadas han sido diversas: laboratorios de ayudas de aprendizaje, centros de recursos, centros de autoestudio, centros de ayudas audiovisuales, o unidad de aprendizaje. Percival y Ellington (1984) por su parte, nos hablan que suelen utilizarse tres denominaciones básicas: centros de recursos, laboratorios de ayudas del aprendizaje y centros de autoestudio. Nosotros en nuestro trabajo, vamos a utilizar la de centros de recursos, por ser la más general y utilizada en nuestro contexto.

Como ya señalamos en otro trabajo Cabero (1996), podemos discriminar entre dos perspectivas de entenderlos, las que vamos a denominar como perspectiva técnica-instrumental y perspectiva didáctica-curricular. Centrarnos en una $u$ otra, repercutirá desde las funciones que puede desempeñar la institución, los medios que disponga, y el personal que puede formar parte de la misma.

Las diferencias básicas entre ambas concepciones radican que en la primera se le conciben como centros exclusivos de almacenaje, préstamo y producción de medios técnicos audiovisuales, informáticos o telemáticos. Mientras que la segunda, desempeñan verdaderos lugares de aprendizaje puestos a disposición tanto de los profesores como de los estudiantes. Con ello no queremos decir, que en la segunda de las perspectivas no se den funciones de la primera. En síntesis podemos decir, a los centros que se mueven en torno a la primera perspectiva se les puede considerar como meros centros de préstamo audiovisual e informático, y a los que se desenvuelven en la segunda, como centros de aprendizaje y enseñanza. Aunque como es bien sabido, en estado puro nos encontramos pocos elementos, más el hecho que las nuevas redes de comunicación han transformado los espacios de ubicación de los medios para que trabajen los alumnos e interaccionen los profesores.

En la primera de las perspectivas todo girará en torno al medio y a sus componentes técnicosestéticos que lo constituyen, mientras que en la segunda, los medios son percibidos como un elemento curricular más del sistema educativo, que funcionará en interacción con el resto de componentes, y que posibilitarán determinados entornos de aprendizaje.

Para diferenciar y clasificar los centros de recursos podemos contemplar dos criterios apuntados: producción/distribución y niveles de enseñanza. Dentro de la primera perspectiva podríamos distinguir entre centro para la producción de recursos, centros para facilitar el empleo de los productos ya producidos y centros mixtos. $Y$ en la segunda, diferenciar entre centro de recursos universitarios, y centros para enseñanzas de secundaria y primaria, o para alumnos con necesidades especiales.

Digamos desde el principio, que a los centros que se dedican a facilitar y distribuir medios audiovisuales e informática, los podemos considerar como mediatecas, y no los abordaremos en nuestro trabajo, ya que creemos que la idea del centro de recursos exige algo más que la mera distribución y catalogación de los recursos.

Nosotros más que entrar en definiciones concretas de lo que podemos entender por centro de recursos, nos parece más oportuno aportar algunas de sus características básicas definitorias, y al respecto podríamos destacar tres: son espacios donde se centralizan los medios; los medios básicamente son audiovisuales, informáticos, multimedias y digitales telemáticos; y su uso prioritarios está destinado a la enseñanza, independientemente del nivel educativo al que nos refiramos, y de que el usuario base sea el profesor o el alumno.

Ahora bien, por encima de estas características no podemos olvidar una de sus condiciones básicas, como afirma Vidorreta (1993: 18): "se concibe como un lugar de aprendizaje donde se encuentran toda clase de materiales debidamente organizados y fácilmente accesibles para su uso por parte de profesores y alumnos donde existen facilidades para la elaboración y adaptación de materiales didácticos". 
Con nuestra primera característica, ser espacios centralizados de medios, nos queremos referir a que son espacios físicos donde se introducen los medios, con prestaciones, teóricamente elevadas, para facilitar la observación y audición de documentos, así como el archivo y mantenimiento de los mismos. Es decir, son espacios especializados para la interacción con los medios. Con la segunda, lo que queremos es diferenciar entre aquellos espacios destinados a medios como los impresos y de laboratorio, y los dirigidos a los medios técnicos audiovisuales, informáticos y multimedias en sus diferentes versiones que son los que forman parte típica de estas instituciones. Y con la última, reclamar su sentido y finalidad básica, la educación y la instrucción en sus diversas modalidades, es decir el ser centros de aprendizaje y enseñanza, pudiendo ser sus usuarios tanto los profesores como los estudiantes.

Realizadas estas precisiones es el momento de preguntarnos sobre cuáles pueden ser sus niveles de aplicación y concreción los mismos.

En función del alcance o de la cobertura de los centros a los que atienda, podemos diferenciar dos tipos. Los que vamos a denominar como centro de recursos del propio centro, o centros de recursos individuales, y centros de recursos cuyo alcance es de varios centros, o centros de recursos colectivos. Estos últimos, según su grado de amplitud los podríamos diferenciar en centros zonales, locales, provinciales, regionales, o nacionales. También nos podemos encontrar con aquellos centros que se dedican a atender a una única institución, y los diversos centros que lo forman, como son los centros de recursos universitarios.

Cada uno de ellos, además del alcance y número de centros a los que atiendan se diferenciarán por las funciones que pueden desempeñar, los materiales que podrán disponer, las actividades que realizarán y el personal necesario para atenderlo.

Digamos desde el principio que para nosotros si bien inicialmente los centro de recursos individuales, podrían tener cierto sentido por razones meramente operativas, como eran la escasez de medios y la necesidad de contar con espacios adecuados para su utilización. En la actualidad, la operatividad y flexibilidad de los nuevos materiales y medios que se están acercando al aula, hace que estos sean menos necesarios que antes, y se conviertan exclusivamente en espacios de almacenaje y centralización. Tampoco podemos olvidar que la arquitectura escolar ha mejorado en los últimos años, prestándole atención a las condiciones del aula, para que puedan ser utilizados diversos recursos de enseñanza; así como también que se están llevando conexiones de Internet al aula, se están incorporando redes inalámbricas en los centros, y que las nuevas tecnologías propician la interconexión e interacción de diferentes tecnologías y sistemas simbólicos.

En el centro los medios pueden ser organizados en varios niveles, como hemos presentado anteriormente, que van desde el planteamiento de que cada profesor se haga responsable de su propio material, hasta una organización conjunta para todos los profesores, por departamentos, semanarios, ciclos o niveles. Cada una de ellos tienen sus ventajas e inconvenientes y requieren niveles diferentes de organización, implicando las últimas la necesidad de elegir responsables de medios, establecer normas de uso, o elaborar catálogos.

Si los centro de recursos de atención individual, deben desempeñar actividades claramente relacionadas con sus profesores y estudiantes, los colectivos, independientemente del número de centros que atiendan, deberán desempeñar actividades más amplias, como por ejemplo, las relacionadas con la producción de medios adaptados a los profesores y estudiantes de la zona, evaluación de materiales, formación y perfeccionamiento del profesorado, y evaluación de las necesidades formativas de sus profesores.

El número, características y la formación del personal, debe de variar lógicamente en función del tipo de centro. Algunos podrán ser atendidos exclusivamente por técnicos de imagen y sonido, y otros requerirán la intervención de pedagogos expertos en la utilización y diseño de medios y recursos dentro de los contextos de enseñanza-aprendizaje. 
Las funciones que se le han asignado según diferentes autores (Vidorreta, 1982; Juncosa, 1984; Álvarez y Luque, 1984, Cabero, 1986; Hug, 1992; Segovia, 2000) son bastante amplias y nosotros sin ánimo de acotarlas las podríamos especificar en las siguientes: instrumental, servicio de información, diseño y producción de medios, selección y evaluación del material, formación y perfeccionamiento del profesorado, e investigación. Funciones que no deben de percibirse de forma aislada sino en estrecha relación, y respondiendo a las líneas directrices que se hayan formulado para el centro de recursos, aunque también es cierto que cada una de las funciones generarán ámbitos específicos de actuación.

Aunque por cuestión de espacio no nos detendremos en analizar pormenorizadamente cada una de ellas, si nos gustase realizar algunos comentarios de las mismas. Así la función instrumental es una de las típicas desempeñadas por los centros de recursos, esta función se concreta en el préstamo de material audiovisual, informático y multimedia a los profesores de la zona, control y mantenimiento de los equipos que tenga bajo su responsabilidad, coordinación del material técnico existente en los centros de la zona, y en algunos tipos de centros de recursos la posibilidad de distribuir materiales que vengan asignados desde la Administración.

Esta función que podría ser criticada por su simplicidad y tecnicismo, tiene una serie de ventajas adicionales. La experiencia ha ido demostrando la interacción habida entre modestos préstamos y atenciones a profesores, y las implicaciones futuras de éstos demandando cursillos y actividades de formación y perfeccionamiento para la utilización didáctica de las diferentes tecnologías, así como el cambio progresivo de las actitudes de los profesores hacia los medios en general y sus posibilidades concretas en la enseñanza, y en definitiva la realización de propuestas para la integración de los medios dentro del currículum.

En el Secretariado de Recursos Audiovisuales y Nuevas Tecnologías de la Universidad de Sevilla (SAV), esta función ha ido disminuyen progresivamente ya que cada vez son más los centros que poseen unas dotaciones mínimas suficientes para las tareas que realizan de enseñanza y de investigación, utilizándose fundamentalmente el servicio para tareas de apoyo a la organización de Jornadas y Eventos, y actividades puntuales organizadas por la Universidad. Nuestra experiencia ha demostrado que poner en el sitio web, una información sobre los medios que se encuentran disponibles para el préstamo, y las fechas en las cuales ya están comprometidos, facilita que el profesor no tenga que realizar desplazamientos innecesarios.

La función anterior generará la necesidad de dominar técnicas específicas para el registro, la catalogación, el control, el préstamo, el mantenimiento y el almacenaje. Técnicas sobre las que el lector comprenderá que no nos detengamos, pero que deben de ser contempladas desde los inicios del centro de recursos, ya que sería una gran contradicción crear una institución que al fin y al cabo lo que pretende es la organización racional de los recursos, y no establecer los mecanismos necesarios para ello, siempre teniendo en cuenta, que cuanta menor burocratización y más racionalización flexible, se facilitará el acercamiento de los profesores a los medios y su utilización.

El servicio de información está claramente relacionado con la función señalada anteriormente, ya que se trata de establecer mecanismos para que el profesor y alumno puedan acceder a documentación y bibliografía sobre la utilización técnica y didáctica de los recursos, orientarlos y asesorarlos sobre la adquisición de medios en función de sus parámetros técnicos-didácticos y de la experiencia que se haya podido recoger de otros centros de la zona, e informar al profesorado sobre los nuevos materiales que se vayan incorporando al centro de recursos o que vayan apareciendo en el mercado

Para nosotros este servicio de información no debe de limitarse a los aspectos anteriormente señalados, que podríamos considerar como de servicio de información meramente técnica, sino que deben de alcanzar dos aspectos que consideramos significativos e importantes desde un punto de vista didáctico-educativo: la difusión de experiencias de los profesores, y la creación de mecanismos de conexión entre los profesores de la zona para facilitar el intercambio de experiencias y la producción cooperativa de materiales de enseñanza. Ello se puede hacer por diversos procedimientos, que van desde la organización de encuentros y Jornadas, hasta la elaboración de un periódico o revista informativa. 
Para un correcto funcionamiento de los aspectos anteriores, puede ser conveniente adoptar medidas de control de calidad, en cuanto a la calidad del servicio y calidad del funcionamiento de los equipos.

La función de diseño y producción es otra de las tradicionalmente desempeñadas. Ahora bien, tal función debe claramente de especificarse y matizarse, ya que no se trata de construir centros de producción audiovisual, informática o multimedia, sino por el contrario, centro de producción audiovisual o informática para la educación, ello automáticamente nos lleva a una reflexión, y es que lo técnico en todo momento debe estar supeditado a lo educativo y didáctico. No se trata por tanto de elaborar materiales para su reproducción en circuitos comerciales, sino para los contextos educativos de la zona, o para proyectos de interacción entre centros.

Respecto a las producciones es importante que exista una estrecha colaboración entre los profesores de la zona y el personal técnico, administrativo o de gestión del centro de recursos, de manera que los profesores se impliquen en el diseño y guionización de los materiales. Nosotros en el "Secretariado de Recursos Audiovisuales" de la Universidad de Sevilla, llevamos varios años con una experiencia que consideramos positiva, y es la de abrir diferentes convocatorias para la producción de vídeos didácticos, vídeos de prácticas, multimedias, y materiales formativos para la red (http://www.sav.us.es ). En estos casos se les pide a los profesores que presenten unos guiones, entendiéndolos éstos desde una perspectiva flexible, que una vez aprobados son realizados pro profesionales didácticos y técnicos de los medios, con equipos profesionales de producción. Nuestra experiencia ha permitido que podamos tener ya más de 800 títulos en vídeo, cerca de 150 materiales multimedias y más de 40 asignaturas completamente en la red.

A continuación presentamos las bases de las convocatorias que se han aplicado en el año 2004 para la selección de los proyectos de vídeo.
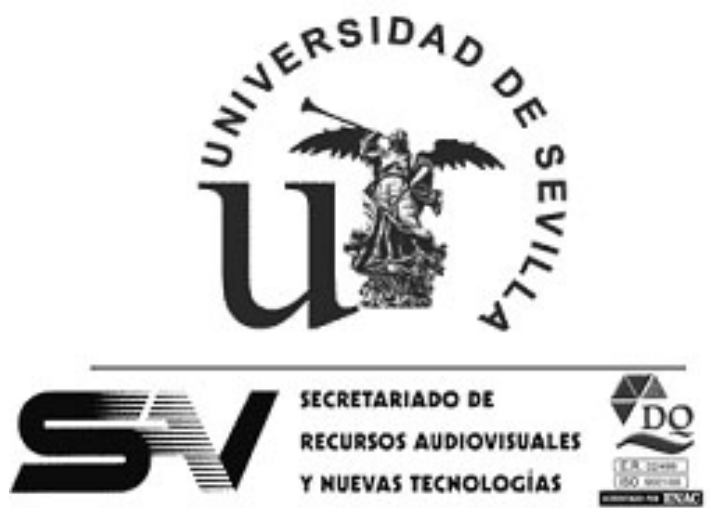

\author{
Secretariado de Recursos Audiovisuales y Nuevas Tecnologías \\ Vicerrectorado de Calidad y Nuevas Tecnologías \\ Universidad de Sevilla \\ BASES DE LA CONVOCATORIA DE PRODUCCIÓN DE GUIONES VIDEOGRÁFICOS \\ DIDÁCTICOS 2004.
}

- El Secretariado de Recursos Audiovisuales y Nuevas Tecnologías realizará tres vídeos de carácter didáctico en la presente convocatoria.

- Los vídeos producidos por la presente convocatoria estarán a disposición de los estudiantes (en la videoteca del SAV), y de la Comunidad Universitaria pudiendo ser duplicados en el Secretariado, con el único cargo de concepto de copia. Al mismo tiempo se enviarán dos copias a la biblioteca del centro.

- La presente convocatoria sólo aceptará vídeos de carácter didáctico para estudiantes.

- Es imprescindible la presentación de un guión o descripción de los vídeos a producir.

- El simple hecho de presentar un proyecto implica la aceptación de sus bases.

- Para la aprobación del proyecto se tendrá en cuenta el número de vídeos que formen la serie; el coste de la producción; su interés didáctico; la abundancia o innovación de la temática dentro de las anteriores producciones de éste Secretariado; el aval científico y la adecuación a los modos de expresión y contenidos propios del documental científico-didáctico.

- El plazo de presentación de proyectos será del 1 al 21 de Mayo del 2004

- Los guiones se entregarán en el "Secretariado de Recursos Audiovisuales y Nuevas Tecnologías" 
(en la calle Porvenir, 27, edificio Corominas) de la Universidad de Sevilla, con registro de entrada. - A esta convocatoria podrán acceder todos los profesores, individualmente o en colectivo, de la Universidad de Sevilla.

- Los profesores que deseen participar en la convocatoria deberán cumplimentar el modelo de hoja de solicitud que se les facilitará en este Secretariado y a través de nuestra página Web http://www.sav.us.es/ , así como una carta del Director del Departamento o del Grupo de Investigación, donde se haga referencia al interés de la producción de vídeos de prácticas para los estudiantes, o del interés didáctico.

- Los profesores responsables de los guiones aprobados se comprometerán a su realización en la fecha indicada por el Secretariado de Recursos Audiovisuales y Nuevas Tecnologías; a las gestiones de producción, permisos y licencias legales tanto de los espacios físicos donde se desarrollen las grabaciones como a los medios necesarios para la producción de los vídeos o material multimedia; a mantener una entrevista, como mínimo, con el Director del Secretariado y a la elaboración de una pequeña guía orientativa de cómo pueden ser utilizados los diversos materiales.

- La propiedad intelectual será del profesor responsable del proyecto, y los derechos de distribución serán para el Secretariado de Recursos Audiovisuales y Nuevas Tecnologías de la Universidad de Sevilla. A los materiales producidos le será asignado un número de ISBN.

- El Secretariado de Recursos Audiovisuales y Nuevas Tecnologías se compromete a la realización de los vídeos en sistema profesional y a la entrega de dos copias de formato doméstico al profesor responsable del vídeo.

- El simple hecho de presentar un proyecto implica la aceptación de sus bases.

La convocatoria será resuelta por una Comisión formada por el Vicerrector de Calidad y Nuevas Tecnologías, el Director del Secretariado de Recursos Audiovisuales y Nuevas Tecnologías, un miembro del CADUS y dos Técnicos del Secretariado. La decisión se hará pública antes del 15 de junio del año 2004.

Los guiones no aceptados podrán retirarse en el Secretariado de Recursos Audiovisuales de la Universidad de Sevilla.

En esta función de diseño y producción no se debe caer en el error, de intentar producir exclusivamente aquellos medios y recursos que requieren alta tecnología y complejidad, y pensar siempre en aquellos recursos tecnológicos más sofisticados. Sino por el contrario en elaborar materiales que vayan a ser claramente utilizados por los profesores, porque a bien tengan materiales de equipo para su utilización, o se encuentren dentro de su frecuencia de utilización.

Una cuestión importante en la producción de materiales, es lo referido a su propiedad intelectual y los derechos de autor, que crean ciertos recelos en los profesores para la producción de materiales, sobre todo cuando estos van a ser ubicados en la red. Nuestra experiencia nos lleva a señalar que es importante desde el principio indicarles que participan en una experiencia que desde el centro se gestionará el ISBN de la producción y se le asignará un depósito legal. Como señala Bates $(2001,139)$ : "Nada suscita más confusión, mala información y paranoia como el tema de la propiedad intelectual y el copyright en torno al desarrollo y uso de materiales digitales".

Es importante establecer algún modelo de contrato de manera que desde el principio queden claro aspectos como: de quién es la propiedad intelectual del material, si los derechos de autor van a ser compartidos entre la institución y el profesor, o qué beneficios obtendrá el profesor si hay una venta o distribución económica del material que han producido. Ello va creando una cultura de confianza que el profesor colabora con más seguridad, y se facilita después la distribución de los materiales. Nuestra experiencia nos indica que muchas veces lo único que el profesor solicita es saber qué se está haciendo con sus materiales y quiénes lo están utilizado.

En este aspecto de los derechos de autor Bates (2001, 146-148), nos ofrece una serie de consejos sobre los derechos de autor para los creadores de materiales digitales, que dado su interés reproducimos, algunos de ellos a continuación:

1. Siempre que sea posible, aplicar a la red las mismas normas que a los materiales impresos (en nuestro caso sacamos una versión en CD-ROM a la cual le damos su depósito legal y ISBN).

2. En caso de duda, pedir autorización para utilizar un material ubicado en la red.

3. Proteger siempre los sitios webs con contraseña.

4. Facilitar las lecturas impresas obligadas en formato de impresión, porqué así es más fácil 
obtener el permiso.

5. Facilitar cualquier otra dirección web como enlace de acceso directo, porque así es más fácil obtener el permiso.

6. Aunque a los alumnos se les remita a otra página web, pedir autorización.

7. Facilitar en el sitio una declaración de derechos, informando de que tiene su copryright y que los materiales no pueden bajarse sin permiso.

8. Reconocer siempre el uso de otros materiales, incluso cuando se cuente con la autorización para hacerlo.

9. No conceder autorización a otros de materiales de tercero que hayamos incorporado a nuestro sitio webs.

La función de un centro de recursos respecto a los medios y materiales no se encierra, o no debe de encerrarse, en su mera producción, sino que también debe de procurar evaluar el material disponible en función de su adecuación a los profesores y alumnos a quienes atienda. Como es bien sabido ninguna tecnología es transferible directamente a cualquier contexto educativo, y desde esta perspectiva los centro de recursos pueden cumplir una función verdaderamente significativa para analizar las posibilidades y limitaciones de determinados materiales, y elaborar, si fuera necesario, guías de asesoramiento de utilización. Guías que deben de concebirse desde una perspectiva abierta y que progresivamente deben enriquecerse con las aportaciones de los profesores que utilicen el material: dificultades que han encontrado en su utilización, formas en que lo usaron y resultados obtenidos, adecuación a los alumnos, vocabulario no comprendido, ritmo, lo óptimo de su duración...

Esta evaluación de materiales puede hacerse de acuerdo a diversas estrategias que van desde la evaluación por expertos a la evaluación "por" y "desde" los usuarios, y con la aplicación de diversas técnicas como los cuestionarios, las entrevistas, las escalas de actitudes, los grupos de discusión...; y alcanzar o centrase en diferentes aspectos, técnicos, económicos, contenidos, relación al público al que van destinados, organización interna de la información... (Cabero, 1999).

En este sentido puede ser de gran ayuda que cada medio tenga un historial de utilización, donde el profesor que lo ha utilizado, indique los aspectos positivos que ha encontrado, las limitaciones que ha tenido que resolver por algún procedimiento, y la forma de incorporarlo a la práctica educativa que recomienda.

Como ya hemos dicho, una de las realidades con las que nos encontramos con estos elementos curriculares, es el bajo nivel de formación que el profesorado suele poseer para su utilización. Y por no ser redundante sobre el tema, decir únicamente que los centros pueden adquirir esta competencia. Ahora bien, desde nuestro punto de vista no deben limitarse a mera organización de curso de formación, sino también utilizar otro tipo de estrategias, como pueden ser: revistas, jornadas, encuentros, grupos de discusión, semanas de proyección de materiales y presentación de materiales,...; para llegar a dinamizar y motivar a los profesores para la utilización didáctica de los medios y la investigación sobre los mismos. EI SAV de la Universidad de Sevilla en esta línea de motivación lleva publicada una revista que ya lleva más de 20 número y que está sirviendo de intercambio de información y experiencias entre los profesores (http://www.sav.us.es/pixelbit $(23 / 02 / 2004)$.

Para finalizar estas referencias a las funciones que pueden desempeñar los centro de recursos, no podemos olvidarnos de su papel en la investigación de las posibilidades didáctica-educativa de los medios en diferentes aspectos como pragmáticas concretas de utilización, estrategias para el diseño de medios didácticos, actitudes que profesores y alumnos pueden tener hacia los medios concretos y de enseñanza... (Cabero, 2001).

\section{5.- Los medios en la organización y administración de los centros.}

Cada vez va siendo más usual la utilización de los medios en las tareas de administración y gestión del centro, sobre todo del medio informático y de algunos asociados a él. Frente a los complejos programas existentes en el pasado, que requerían el conocimiento y dominio de habilidades necesarias de programación para la utilización de los programas en la actualidad las "suites" o conjuntos de programas permiten no sólo elaborar documentos impresos con calidades cercanas a materiales maquetados para llevar a imprenta, sino también elaborar nuestras propias bases de datos, representar los resultados mediante gráficas o diagramas, o la elaboración de presentaciones colectivas informatizadas multimedia. $Y$ todo ello sin la necesidad de poseer grandes dominios y habilidades técnicas por parte del usuario, y lo que es mejor con una fuerte 
interconexión entre los diversos programas, de manera que una base de datos, puede trasladarse a un procesador de texto para su presentación o al diseñador de gráficos para la obtención de una representación visual.

El software de propósito general, como los procesadores de texto, bases de datos $u$ hojas de cálculo, pueden ser utilizados para la gestión y administración de los centros. Estos programas pueden ser adquiridos de forma individual (wordperfect, dbase,...) o en las "suites" a las que anteriormente hicimos referencia. En todos los casos se deberá tener en cuenta la fácil transferencia de los datos de un programa a otro y los que son de uso coditiano por parte de los profesores.

A la hora de la elección de los programas individuales o de las "suites" puede ser recomendable tener en cuenta una serie de aspectos, como son:

- Existencia de documentación en castellano.

- Facilidad de conexión de los diferentes programas y transferencia de los datos a los diferentes programas.

- Adecuación a las características técnicas de los medios disponibles en el centro.

- Facilidad de manejo.

- Programas informáticos que los profesores suelen utilizar.

- En el caso de las bases de datos que permitan buscar los registros, tanto de forma general como en función de una condición de búsqueda establecida, discriminar entre los registros que poseen una determinada condición y los que no, emitir un informe impreso de determinados campos,...

- Respecto a las hojas de cálculo, que permitan realizar los cálculos aritméticos elementales y los estadísticos descriptivos básicos (media, desviación típica, porcentajes,...), y la presentación gráfica de los resultados.

Los usos fundamentales de los medios como instrumentos de ayuda a la organización y administración de los centros, los podemos concretar en los tres siguientes: 1) Gestión administrativa y económica del centro, 2) Gestión académica de los alumnos, y 3) Gestión de los materiales existentes en la biblioteca o en otros departamentos del centro.

Los medios informáticos pueden ser de gran ayuda a los centros para tener organizado todo el expediente académico de los estudiantes, desde su registro de entrada hasta las calificaciones académicas, incidencias, faltas de asistencia a clase, etc. Y no sólo del expediente de los alumnos, sino también de los profesores: dirección particular, teléfono, partes de baja, horarios de clase, asignaturas impartidas, cambios de asignaturas a lo largo de su permanencia en el centro,... Al mismo tiempo, cada vez se está ampliando la utilización de las secretarías virtuales para que, por una parte, los alumnos realicen todas las gestiones administrativa que tienen que realizar en los centros: matricula, anulación de asignaturas, becas,..., y por otra, porque los profesores pueden acceder a las listas de clase, los expedientes de los alumnos o las calificaciones de los alumnos.

Los medios que analizamos pueden ser de gran ayuda a las direcciones de centro para la ardua tarea de la confección y organización de los horarios sin tener que repetir todo el proceso y ensayar y combinar diferentes alternativas, permitiéndole combinar de forma rápida y fiable tanto las variables referidas a los alumnos (obligatorias y optativas) como las referidas a los profesores (asignaciones horarias y preferencias), o a las zonas de utilización del centro (gimnasio, laboratorios de física, laboratorios de idiomas, sala de informática,...). También permitirán la realización del horario desde diferentes perspectivas: general del centro, para los profesores, para cursos concretos, para el horario de tutoría, o para la utilización de zonas específicas del centro.

En cuando al alumno, pueden resultar de gran ayuda para la gestión del expediente académico, boletines de calificaciones, control de asistencia, y carnet escolar. Estos datos pueden enriquecerse con la incorporación de informaciones de los gabinetes de orientación de los centros, y los resultados que allí se hubieran obtenido, en cuanto a su inteligencia, aptitudes, estilos de aprendizaje, ... 
evaluación mecánica o informática, como queramos denominarla, de los estudiantes. Ello puede realizarse desde una doble perspectiva, por una parte mediante la corrección y calificación mecánica de las pruebas objetivas realizadas por los estudiantes, para lo cual se requiere desde hojas especiales para la cumplimentación de la prueba por los alumnos hasta lectores ópticos que por medio de programas especiales los corrijan, y por otra, la interacción directa del estudiante con un programa que posee una base de datos de preguntas de los contenidos del programa oficial a cursar por el estudiante, respecto a los cuales debe contestar el estudiante de forma objetiva, corrigiendo automáticamente el programa la ejecución del estudiante y asignándole la calificación correspondiente.

Respecto a la gestión económica del centro, su utilización puede ser similar a las realizadas con estos medios en otras empresas: elaboración del presupuesto económico anual, el control del gasto teniendo en cuenta tanto las entradas como salidas, incorporación de nuevos presupuestos, ... Todo ello, permitiéndonos la representación gráfica de los resultados, y la comparación, global o por capítulos, con mensual, trimestralmente o con otros años. Cada vez más, grandes bases de datos y programas específicos, gestionan la administración de los centros.

Ni que decir tiene que los medios informáticos y telemático, son de gran ayuda para el control de los materiales didácticos, sean estos impresos, informáticos o audiovisuales, de los que dispone el centro. Facilitando su catalogación, la información a los usuarios, su préstamo y control, y el control sobre su grado de utilización y necesidad o no de adquisición de nuevas versiones. Cada vez se tenderán más a espacios virtuales de organización y administración de los centros.

Para finalizar en la gráfica de la figura $n^{\circ} 4$, presentamos una síntesis de las posibilidades que los medios pueden aportar a la gestión y administración del centro. 


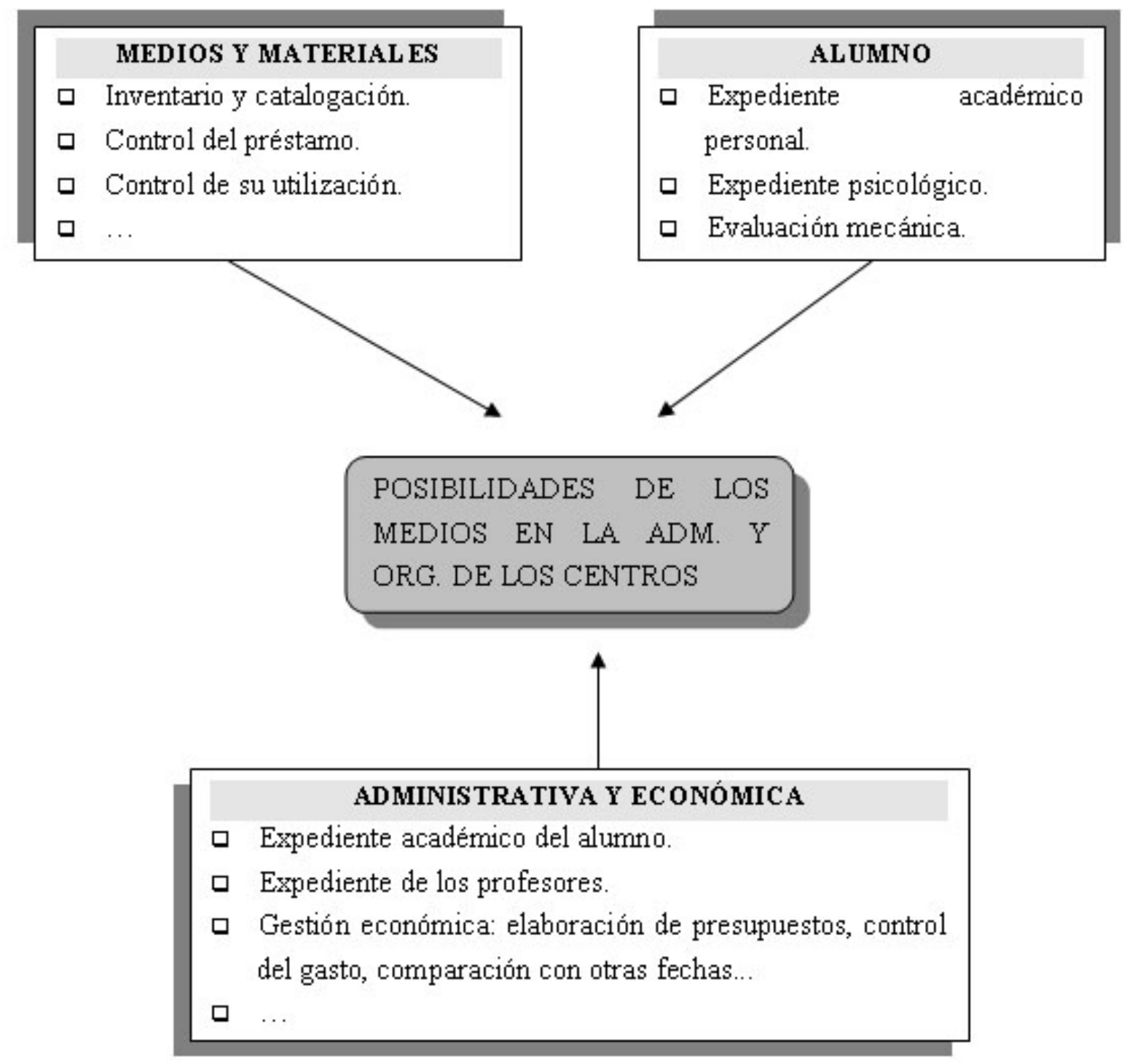

Fig. 4.- Posibilidades de los medios en la organización y administración de los centros.

Referencias

ALVAREZ, E. y LUQUE, I. (1984) "El centro regional de Asturias". Apuntes de Educación. Dirección y Administración escolar, julio-septiembre, 7-9.

BARBERÁ, E. y otros (2001): Enseñar y aprender a distancia: ¿es posible?", http://www.uoc.es/web/esp/art/uoc/0105018/ensapren.html (14/02/02).

BATES, A.W. (2001): Cómo gestionar el cambio tecnológico. Estrategias para los responsables de centros universitarios, Barcelona, Gedisa.

CABERO, J. (1996): Organizar los recursos tecnológicos. Centros de recursos, en GALLEGO, D. y otros (coords): Integración curricular de los recursos tecnológicos, Barcelona, Oikos-Tau, 403-425.

CABERO, J. (1998): Los usos de los medios audiovisuales, informáticos y las nuevas tecnologías, Sevilla, Grupo de investigación didáctica. (http://tecnologiaedu.us.es/bibliovir/libros0.htm (19/02/2004).

CABERO, J. (1999): La evaluación de medios audiovisuales y materiales de enseñanza, en CABERO, J. (ed): Tecnología Educativa, Madrid, Síntesis, 87-106.

CABERO, J. (1999): La organización de los medios en el sistema educativo y su impacto en las organizaciones educativas, en CABERO, J. (ed): Tecnología educativa, Madrid, Síntesis, 163-179. CABERO, J. (2003): "Las nuevas tecnologías en la actividad universitaria", Píxel-Bit. Revista de medios y educación, 20, 81-100.

CABERO, J. (dir) (2002): Las TICs en la Universidad, Sevilla, MAD.

CABERO, J. y otros (2001): "Las influencias de las nn.tt. en los entornos de formación. Posibilidades, desafíos, retos y preocupaciones.", Comunicación y Pedagogía. Nuevas Tecnologías y Recursos didácticos, 175, 48-54.

CHAN, M.E. (2002): La construcción de objetos de aprendizaje, en: ORTíZ, M.G. y PÉREZ, M (comps): Hacia la construcción de la sociedad del aprendizaje, Guadalajara, Universidad de Guadalajara, 111-132. 
DOBROV, G.M. (1979): "La technologie en tant qu’organisation", Revue Internationale des Sciences Sociales, XXXI, 4, 628648.

DUARTE, A. y CABERO, J. (1993): Modelos de organización de centros y medios de enseñanza, en CORONEL, J.M. y otros (eds): Cultura escolar y desarrollo organziativo, Sevilla, Grupo de Investigación Didáctica, 701-720.

HUG, W.E. (1992): Medios de comunicación, Administración de los programas de los, en HUSEN, T. y POSTLETHWAITE, T.L. (eds): Enciclopedia Internacional de la Educación, Madrid, Vicens Vives-MEC, vol. 6, 3853-3856.

JUNCOSA, R. (1984) "Los centros de recursos pedagógicos de Cataluya". Apuntes de Educación. Dirección y Administración escolar, julio-septiembre, 3-6.

KAGEL, M.M. (2003): Estudio de los cambios organizacionales producidos por un proyecto de informatización desarrollado en el entro escolar, Málaga, Facultad de Ciencias de la Educación, tesis doctoral inédita.

LAGUÍA, M.J. y VIDAL, C. (1987): Racons d'activitat a l'escola bressol i parvulari, Barcelona, Graó.

LORENZO, M. (1996): La organización de los medios y recursos en los centros, en CABERO, J. y otros (coords): Medios de comunicación, recursos y materiales para la mejora educativa II, Sevilla, Kronos, 9-40.

MARTÍNEZ, F. (2002): TIC y globalización, en AGUIAR, M.V. y otros (coords): Cultura y educación en la sociedad de la información, La Coruña, Netbiblo, 47-59.

MCT (2003): Aprovechar la oportunidad de la sociedad de la información en España, Madrid, MCT. MECD (2003): Los desafíos de las tecnologías de la información y la comunicación en la educación, Madrid, MECD.

MECD (2003): Los desafíos de las tecnologías de la información y las comunicaciones en la educación, Madrid, MECD.

PERCIVAL, F. y ELLINGTON, H. (1984): A Handbook of Educational Technology, Londres, Kogan Page.

PERCIVAL, F. y ELLINGTON, H. (984) A handbook of educational technology. Londres, Kogan Page.

SALINAS, J. (1995): Organización escolar y redes: los escenarios de aprendizaje, en CABERO, J. y MARTÍNEZ, F.: Nuevos canales de comunicación en la enseñanza, Madrid, Editorial Centro de Estudios Ramón Areces, 89-117.

SALINAS, J. (2003). Acceso a la información y aprendizaje informal en Internet, Comunicar, (en prensa).

SEGOVIA,

SEGOVIA, D. (2000): La organización de los centros y las nuevas tecnologías de la información y comunicación, en CABERO, J. (ed): Nuevas Tecnologías aplicadas a la educación, Madrid, Síntesis, 229-251.

SEGOVIA, J.D. (2000): La organización de los centros y las nuevas tecnologías de la información y comunicación, en CABERO, J. (ed): Nuevas tecnologías aplicadas a la educación, Madrid, Síntesis, 229-250.

VIDORRETA, C. e IGUALADA, A. (coord) (1986): Organización de los recursos en los Centros escolares. Análisis de centros de Recursos y de sus espacios, Cuenca, Dirección Provincial de educación.

VIDORRETA, Ch. (1982): Cómo organizar los centros de recursos. Madrid, Anaya.

VIDORRETA, Ch. (1993): Estudio evaluativo de los centros de recursos (CR)", Bordón, 45, 1, 1726.

Revelec2/revelec15

-7d22a01f30152 Content-Disposition: form-data; name="camino" 